\title{
Factors that affects the dielectric properties of natural fibre reinforced hybrid biocomposite
}

\author{
Nishanthi Sunthrasakaran ${ }^{1}$, Nor Akmal Mohd Jamail ${ }^{2}$, Rahisham Abd. Rahman ${ }^{3}$, \\ Md Nor Ramdon Bin Baharom ${ }^{4}$, Qamarul Ezani Kamarudin ${ }^{5}$, Mohamad Farid Sies ${ }^{6}$, \\ W. Muhammad W. N. Azrina ${ }^{7}$ \\ ${ }^{1,2,3,4}$ Faculty of Electrical and Electronic Engineering, Universiti Tun Hussein Onn Malaysia (UTHM), Malaysia \\ 5,6,7Faculty of Mechanical and Manufacturing Engineering, Universiti Tun Hussein Onn Malaysia (UTHM), Malaysia
}

\begin{tabular}{l} 
Article Info \\
\hline Article history: \\
Received Oct 6, 2018 \\
Revised Feb 8, 2019 \\
Accepted Mar 29, 2019 \\
\hline
\end{tabular}

\section{Keywords:}

Electrical properties

Fibre content

Hybrid composite

Natural fibre

Surface treatment

\begin{abstract}
Almost all research on natural fibre reinforced composite has focused on the mechanical properties of the composite. Drawing on the important factors that effect the end product of composite, this paper reviews electrical properties of hybrid biocomposite when fibre content and surface treatment is varied. The compilation of dielectric constant, dissipation factor, loss factor and moisture absorption reported by researchers has been presented in this paper. The intrinsic characteristic of natural fibre which is hydrophilic is the main drawback that affects the electrical properties of the composite. Alkaline treatment on natural fibre has proven to overcome the hydrophilic characteristic and improves the adhesion between matrix and fibre. Besides that, the percentage of fibre content plays an important role in producing a good natural fibre reinforced hybrid composite. The moisture uptake, dielectric constant, dissipation factor and loss factor of the composite decreases with decreased fibre content.
\end{abstract}

Copyright $\odot 2019$ Institute of Advanced Engineering and Science. All rights reserved.

\section{Corresponding Author:}

Nor Akmal Mohd Jamail,

Faculty of Electrical and Electronic Engineering,

Universiti Tun Hussein Onn Malaysia (UTHM),

86400 Batu Pahat, Johor, Malaysia.

Email:norakmal@uthm.edu.my

\section{INTRODUCTION}

The study of polymer biocomposite has been recognized has an important area of research for over a decade. Polymer biocomposite is a combination of natural fibres and matrix with addition of compatibilizer and coupling agent. Matrix can be classified into fully degradable and partly degradable [1]. Polymer biocomposite is being implemented in many industries such as automotive [2], tissue engineering [3], aerospace application [4], high voltage insulator [5] and many more.

The utilization of natural fibre in polymer or hybrid composite is well known due to the electrical insulating properties. An excellent cable insulator possesses good electrical, physical and mechanical properties. The lower the dielectric constant of an insulator, the better it is [6]. All the natural fibres are hydrophilic in nature with moisture content that reaches $8 \%-12.6 \%$ [7]. However, natural fibre that contributes to water absorption increases the dielectric constant of the composite. This problem can be overcome by alkali treatment.

The electric applications using natural fibre reinforced hybrid composite has been trending lately. The natural fibre reinforced composite materials have been used as dielectric materials in microchips, parts of transformers, terminal, connectors, switches, circuit boards, etc. Therefore, studies of dielectric properties of natural fibers reinforced composite materials and the factors that effect the dielectric constant has been carried out lately [8]. 
The polarizeability of matrix and fillers are determined mainly by interfacial, dipoles, atomic and electronic polarizations [9]. Dielectric constant occurs when material is subjected to an external electric field which causes the material to polarized and store charge [10]. Whereas, the loss tangent $(\tan \delta$ ) or dissipation factor is the ratio of the dissipated electrical power in a material to the total power circulating in the circuit. In other words, measurement of heat that is converted from electrical energy in an insulator [10]. The loss factor ( $\left.\mathrm{e}^{\prime}\right)$ is usually used to express the losses in industrial energy transmission and distribution and can be defined as the average power factor over a given period of time. Dielectric loss factor is measure of loss of energy in a dielectric material through conduction, slow polarization of currents and other dissipative phenomena [6]. It is reported that, most of the elastomer in room temperature have lower dissipation factor. The the dissipation factor ( $\tan \delta$ ), loss factor (dielectric loss, $\left.\mathrm{E}^{\prime \prime}\right)$ and the dielectric constant ( $\left.\mathrm{E}^{\prime}\right)$ [11]

$$
\tan \delta=\frac{E^{\prime \prime}}{E^{\prime}}
$$

\section{HYBRID COMPOSITE}

Hybrid biocomposites are usually designed and processed by the combination of a synthetic fiber and natural fiber (biofiber) in a matrix or with combination of two natural fiber/biofiber in a matrix [12]. Hybrid effect is based on the rule of mixture which then produces an average between those individual fibres utilize. The advantages of using two or more fibre in a single matrix is that the advantages of one type of fibre could complement with what are lacking in the other [13]. The study on natural/natural fibre hybrid composite has been reported by researcher [14].

It is proven that the main advantage of hybridization is it is applicable for many applications such as marine application, power generation, electronic industry, telecom applications, civil construction and thermoplastic application [15]. In general hybridization enhances the mechanical and electrical properties of the composite. However, study on electrical properties of natural fibre reinforced hybrid composite are still not sufficient.

Electrical parameter that can be measured from natural fibre reinforced hybrid composite are dielectric constant, volume resistivity, thermal conductivity, breakdown voltage, water absorption rate, dissipation factor and loss factor. These electrical properties can be influenced by the percentage of fibre content, alkali treatment, fibre length, fibre orientation and frequency [16]. Research on factors that affects the electrical properties of the composite has been reported by a small group of researchers.

\section{ELECTRICAL PROPERTIES OF HYBRID COMPOSITE}

\subsection{Water Absorption} equation:

The percentage of water absorption was calculated by the weight difference using the following

$$
w_{e}(t)=100 \times\left(\frac{w_{t}-w_{0}}{w_{0}}\right)
$$

where $\mathrm{w}_{\mathrm{e}}$ is the relative weight change or water absorption percentage, wt is the weight at the time $t$, and $\mathrm{w}_{0}$ is the initial weight at $\mathrm{t}=0$, and $\mathrm{t}$ is the soaking time.

Journal reported that water absorption of EFB/Kenaf hybrid increases with increasing immersion time. Hybridization of EFB/kenaf fibre decreases water absorption [17]. This is mainly attributed by packed arrangement of hybrid composites and the less hydrophilic nature of kenaf fibre as compared to oil palm EFB fibre. In contrary, journal [18] reported that pineapple-sisal/HDPE composite exhibits highest water absorption rate. Besides that, journal reported that water absorption rate increase with increasing percentage of coir fibre in the composite [19]. The main drawbacks of composite are increased in fibre content which leads to fibre pull out. High fibre content increases the probability of fibre agglomeration which results in regions of stress concentration requiring less energy for crack propagation.

Other than that, for banana/sisal hybrid composite with fibre content ratio 50:50 shows the lowest water uptake percentage [20]. Investigation on effect of fibre content that influences the water absorption characteristic of hybrid composite has been reported by researcher [21]. Roselle/sisal hybrid with $50 \mathrm{~mm}$ fibre length and $10 \%$ fibre content shows the lowest water uptake percentage. Thus, it is proven that fibre length and fibre content plays an important role in water absorption characteristic of a composite. Figure 1 displays the lowest water absorption percentage by natural fibre reinforced hybrid composite based on discussed journal. 
Journal reported on effect of compsite strength based on natural fibre age [22]. It is proven that adhesion property of matured fibre are superior. This is because aged fibre has less moisture absorption. Natural fibre reinforced composite material displays superior mechanical properties under wet conditions when aged fibres are utilized. Stronger composites are invented by adding fibre to to the polymers which is less susceptible to to cracks. However, the composite becomes more prone to moisture absorption due to addition of cellulosic fibres in a polymer. Rate of moisture absorption increase with increasing fibre content. Fibre content should be limited in natural fibre reinforced composite for outdoor condition uses only to attain its intended strength which increases the robustness of the composite and reduce moisture absorption rate [23].

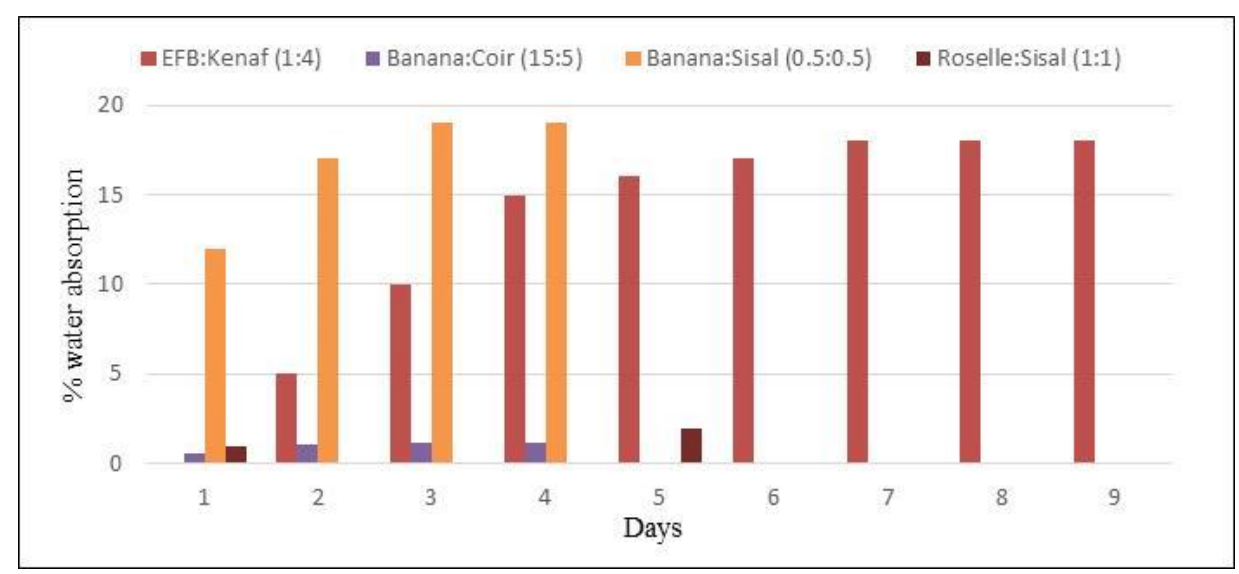

Figure 1. Water absorption percentage by natural fibre reinforced hybrid composite

\subsection{Dielectric Constant}

Dieletric costant is the ratio of the permittivity of a substance to the permittivity of the space. The polarizability characteristic of a material determines the value of dielectric constant. Dielectric properties of material can be categorized into relative permittivity $\left(\varepsilon_{\mathrm{r}}\right)$, electrical conductivity $(\mathrm{k})$ and dissipation factor $(\tan \delta)$. Dieletric constant demonstrates the ability of an insulator to store electrical energy. Whereas, dissipation factor measures the inefficiency of the insulating material which is the reciprocal of the ratio between the insulating material capacitive reactance to its resistance under required frequency. The dielectric constant of the insulating material has to be low in order to achive an excellent insulator property.

\subsubsection{Effect of Fibre Content}

In general, dielectric constant of hybrid composites is based on contribution of interface, atomic, orientation and electronic polarization within the material. Journal reported that dielectric constant increases with increase fibre content over entire range of frequency [11, 24]. On top of that, the higher percentage of jute fibre in the composite contributes to higher dielectric constant due to higher moisture absorption capacity. Dissimilarity in polarization and conductivities of fibre and matrix leads to interfacial polarization. Treated fibres display lower dielectric constant due to increase in hydrophobicity of the fibre [24]. Researcher [11] reported that dielectric constant is the highest when percentage of sisal is $100 \%$. Sisal fibre acquires higher moisture absorption rate compare to coir fibre. Figure 2 display the effect of jute content from two different journal on dielectric constant of hybrid composite [10,24]. The dielectric constant of a material is defined as the measure of the material's ability to become polarized and to store charge when an external field is applied to it through parallel plate acting as a capacitor. At very low frequency, the dielectric properties of the composite materials is influenced by the interfacial polarization due to heterogeneous nature [10].

Journal reported that dielectric properties of oil palm fibre is lower than oil palm shell. The dielectric properties of pineapple leaf fibre reinforced epoxy composite vary with sodium hydroxide treatment and fibre loadings. Dielectric constant of a material is influenced by many factors such as temperature, branching, crystallization and frequency of applied voltage. Furthermore, dielectric constant of the composite increase as the concenteration of mobile dipoles increase due to presence of moisture content in the composite [25]. Chemical treated composite contributes to reduction in water uptake thus leads to reduction in dielectric constant. In addition, studies on dielectric properties of kenaf fibre filled rigid 
polyurethane foam has been reported by researcher [26]. It shows that the dielectric constant is higher with higer fibre content. The dielectric constant of kenaf fibre reduce as the frequency increases provided with different fibre content value. Besides that, the dielectric constant of kenaf fibre increases as the temperature increase with constant frequency of $100 \mathrm{~Hz}$. Moreover, the dielectric constant of kenaf fibre with highest fibre loading is lower compared to jute, palf [16] and bamboo fibre [24].

Dissipation factor of jute/bamboo hybrid composite decreases as the frequency increase and fibre content decrease [24]. It is noticed that the dissipation factor and loss factor increase with fibre loading but decreases with increased frequency. Journal reported that dissipation and loss factor of PALF/Epoxy composite decreases at all frequency but increase with increased in fibre content [16]. Figure 3 display the effect of fibre content of PALF and jute on dissipation factor of hybrid composite. Figure 4 display the effect of fibre content of PALF and jute on loss factor of hybrid composite.

Journal reported that increase in dielectric constant of a composite is caused by higher fibre loading, which was more significant during low frequency. It is proven that dielectric constant decrease when frequency increases in all case. This is because at high frequency, the molecular vibrations are high and hence complete orientation of dipoles does not take place [10]. The dielectric constant, dissipation factor, conductivity and loss factor increases as fibre content increase [27].

Besides that, increase in fibre loading reduces tensile strength and increases the water absorption rate. In addition, increase in fibre content increases the loss modulus and storage modulus. Researcher [28] reported that increased in coconut shell powder (CSP), decreases the elongation at break of PLA/CSP biocomposite and tensile strength. However, it increases the elasticity and the thermal stability. Journal reported that increase in PALF content in PALF/HDPE composite decreases the tensile strength of the composite [29].

\subsubsection{Fibre Orientation}

Fibre orientation can strongly influence the dielectric properties of and interfacial polarization process in composite [30]. Journal [31] reported that under composite structure loading circumstance, short and random fibre orientation forbids the oil palm empty fruit bunch fibre to represent as a strong fibre due to low surface interfacial adhesion competency.

\subsubsection{Fibre Length}

Fibre length is an important factor to be considered to determine the stress distribution and interfacial adhesion. Thickness of oil palm frond fibre is higher than empty fruit bunch and oil palm trunk which leads to poor inter fibre bonding compared to the other two oil palm fibre [32]. Aspect ratio of fibre is the length to diameter ratio. Researchers reported that aspect ratio has a significant effect on the composite properties [32, 33].

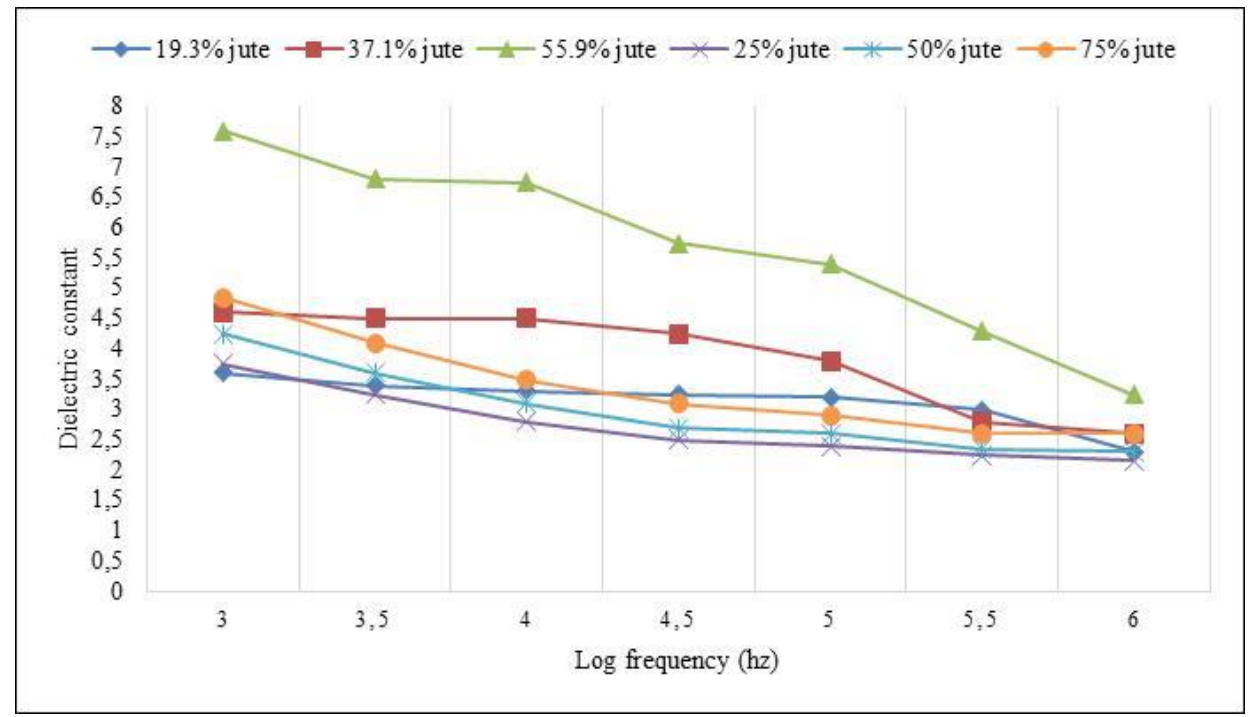

Figure 2. Effect of fibre content on dielectric constant of hybrid composite 


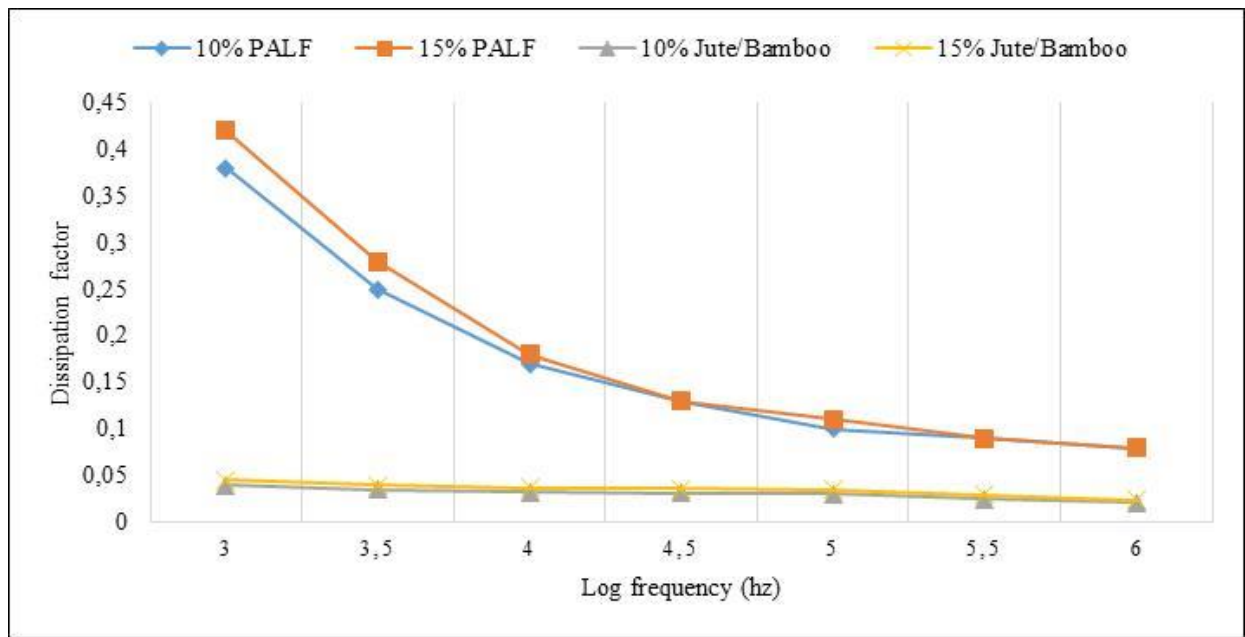

Figure 3. Effect of fibre content on dissipation factor of hybrid composite

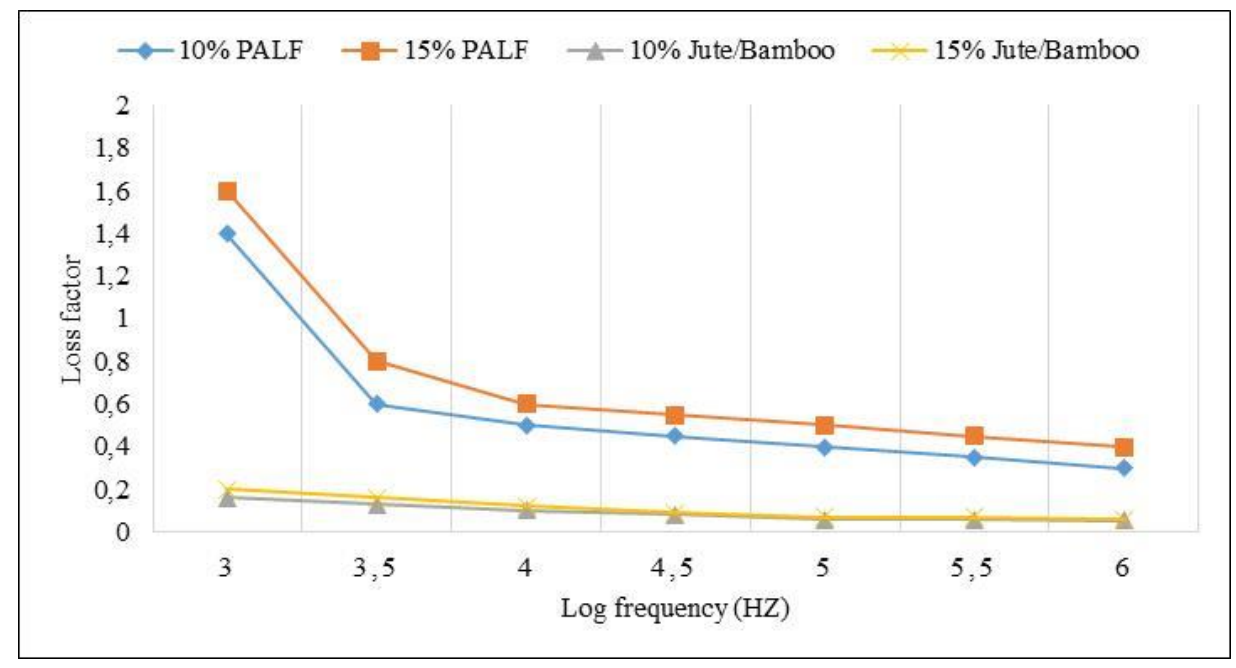

Figure 4. Effect of fibre content on loss factor of hybrid composite

\subsubsection{Effect of Surface Treatment}

Void spaces that are created around the fibres due to weak adhesion between fibre and matrix causes higher water absorption in composite [34]. Aid of fibre modification through alkalization process can reduce the moisture absorption. Alkaline treatment such as sodium hydroxide $(\mathrm{NaOH})$ has the ability to eliminate the hydroxyl groups that bonds with water molecule and reduce the capacity of cellulose hydrogen bonding. Hemicellulose in a fibre is the most hydrophilic compared to lignin and cellulose. It is eliminated partially via alkaline treatment which reduces the ability to absorb moisture content [35]. In general, chemical treatment decreases the rate of moisture absorption but the tendency of water absorption reduction depends on the nature of the chemicals [36].

Surface treatment on natural fibre are mainly done to reduce the hydrophilic characteristic. By doing so, the hydroxyl group $(\mathrm{OH})$ reacts with water molecules and exits the fibre. Besides that, surface treatment improves the adhesion between fibre and matrix. Thus, leads the proper interaction between fibre and matrix. Surface treatment can be divided into few types such as alkali treatment, silane treatment, benzoylation treatment, acetylation treatment, peroxide treatment, isocyanate treatment and many more. Additionally, the the process of coupling between the two constituent are challenging due to different chemical structures of the fibres and matrix. Thus, it leads to ineffective stress transfer throughout the interface of the composites. Therefore, certain chemical treatments on the surface of natural fibres are necessary to overcome this problem. The reagent functional groups of different alkali has different reaction which changes the fibre 
composition and capability of reacting based on the types of fibre [37]. Delignification of fibre occurs when the alkali concentration is higher then optimum condition which leads to fibre damaging [38].

Researcher [10] reported on the dielectric constant of jute/PP yarn composite. As a result, the dielectric constant was reduced after surface treatment. Reduction in number of polar groups and moisture absorption in the composite is achieved by chemical treatment which reduces the hydrophilic nature of jute yarns. Thus, it reduces the dielectric constant owing to reduction in the orientation polarization. Number of voids that exist in jute yarns and matrix can be decreased via chemical treatment by increasing the interfacial adhesion between matrix and fibre. Many research of hybrid composite or polymer composite reports on reduction of dielectric constant after surface treatment. Figure 5 shows the dielectric constant properties of treated jute/bamboo hybrid composite reported by researcher [24]. It displays the same result has previous studies on dielectric constant of treated fibres.

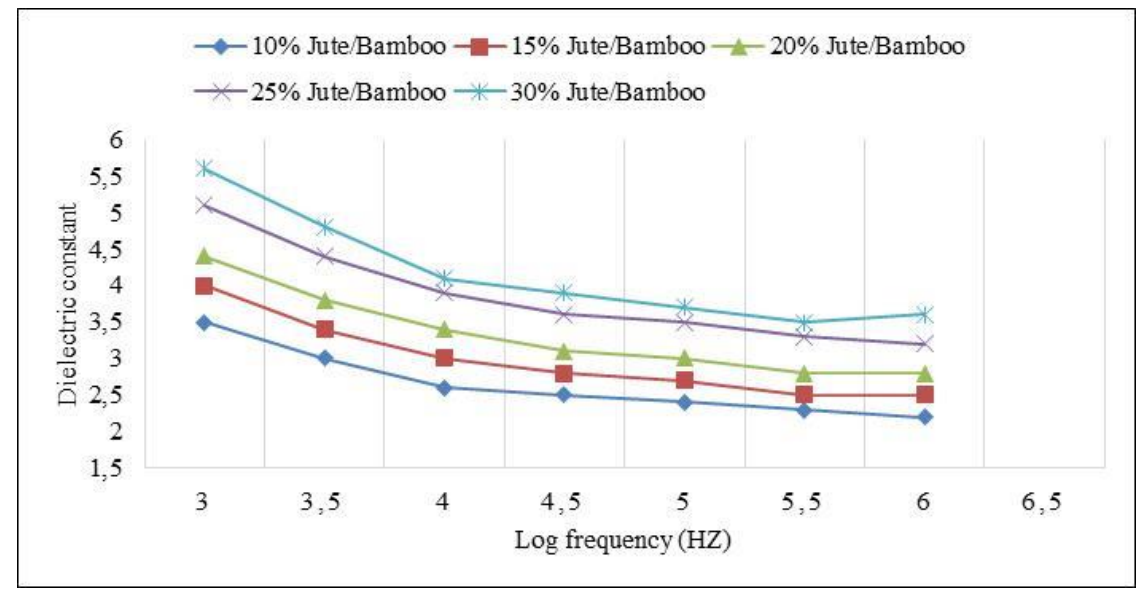

Figure 5. Dielectric constant chemically treated hybrid composite

\section{CONCLUSION}

In hybrid composite, the dielectric constant values decreased with an increase in the frequency. The maximum values of dielectric constant in the lower frequency region were attribute to the interfacial polarization. Alkali treatment specified lowering of $\%$ hemicelluloses and $\%$ lignin. Lower dielectric constant and loss tangent can be seen in alkali treated fibre compared to untreated fibre. However, these values decreased with increase in frequency. This is because at high frequency, the molecular vibrations are high and hence complete orientation of dipoles does not take place. The tendency of water absorption of alkali treated fibre composite is reduced. Whereas, the water absorption properties of hybrid composite increased with immersion time. However, the water absorption rate stops until it reaches saturation point. Thus, alkali treatment is an alternative to overcome water absorption problem. Besides that, by adding fibre content it provides a pathway through matrix to absorb moisture by enchancing matrix porosity. Presence of void space around fibre particle causes poor adhesion between polymer matrix and fibre particles. The loss factor, dissipation factor dielectric constant increased with increasing fiber content. This is because high orientation polarization is caused by increasing in number of polar groups. Last but not least, the dielectric strength being a unique feature of kenaf fibre composite, can be suggested for electrical insulation applications as it posseses lowest dielectric constant value.

\section{ACKNOWLEDGEMENTS}

The authors gratefully acknowledge the Research Management Centre of Universiti Tun Hussein Onn Malaysia under grant GPPS vote H025, Grant Tier 1 vote H090, Kvolt Focus Group Team and High Voltage Laboratory UTHM for the equipment support.

\section{REFERENCES}

[1] J. Sahari and S. M. Sapuan, "Natural fibre reinforced biodegradable polymer composites," Rev. Adv. Mater. Sci., vol. 30, no. December 2012, pp. 166-174, 2011.

[2] M. R. Mansor, S. M. Sapuan, E. S. Zainudin, A. A. Nuraini, and A. Hambali, "Conceptual design of kenaf fiber

\footnotetext{
Factors that affects the dielectric properties of natural fibre reinforced hybrid... (Nishanthi Sunthrasakaran)
} 
polymer composite automotive parking brake lever using integrated TRIZ-Morphological Chart-Analytic Hierarchy Process method," Mater. Des., vol. 54, pp. 473-482, 2014.

[3] A. Rogina, "Applied Surface Science Electrospinning process : Versatile preparation method for biodegradable and natural polymers and biocomposite systems applied in tissue engineering and drug delivery," Appl. Surf. Sci., vol. 296, pp. 221-230, 2014.

[4] V. K. Thakur, M. K. Thakur, P. Raghavan, and M. R. Kessler, "Progress in green polymer composites from lignin for multifunctional applications: A review," ACS Sustain. Chem. Eng., vol. 2, no. 5, pp. 1072-1092, 2014.

[5] N. A. M. Jamail et al., "Effect of nanofillers on the polarization and depolarization current characteristics of new LLDPE-NR compound for high voltage application," Adv. Mater. Sci. Eng., vol. 2014, 2014.

[6] N. Nayak, H. N. Reddappa, G. Kalagi, and V. Bhat, "Electrical Insulating Properties of Natural Fibre Reinforced Polymer Composites ; A Review," vol. 6, no. 08, pp. 165-170, 2017.

[7] A. K. Mohanty, M. Misra, and G. Hinrichsen, "Biofibres, biodegradable polymers and biocomposites: An overview," Macromol. Mater. Eng., vol. 276-277, pp. 1-24, 2000.

[8] S. Kumar, B. Gangil, and V. K. Patel, "Physico-mechanical and tribological properties of Grewia Optiva fiber/bioparticulates hybrid polymer composites," AIP Conf. Proc., vol. 1728, 2016.

[9] E. J. Tomlal, P. C. Thomas, K. C. George, K. Jayanarayanan, and K. Joseph, "Impact, tear, and dielectric properties of cotton/polypropylene commingled composites," J. Reinf. Plast. Compos., vol. 29, no. 12, pp. 1861-1874, 2010.

[10] G. George, K. Joseph, E. R. Nagarajan, E. T. Jose, and K. C. George, "Composites : Part A Dielectric behaviour of PP / jute yarn commingled composites : Effect of fibre content, chemical treatments, temperature and moisture," Compos. Part A, vol. 47, pp. 12-21, 2013.

[11] A. P. Haseena, G. Unnikrishnan, and G. Kalaprasad, "Dielectric properties of short sisal / coir hybrid fibre," vol. 14, no. 7, pp. 763-786, 2007.

[12] M. J. John and S. Thomas, "Biofibres and biocomposites," Carbohydr. Polym., vol. 71, no. 3, pp. 343-364, 2008.

[13] M. Jawaid, N. Saba, O. Y. Alothman, H. P. S. A. Khalil, and M. Mariatti, "Thermal conductivity behavior of oil palm/jute fibre-reinforced hybrid composites," AIP Conf. Proc., vol. 1901, 2017.

[14] C. Dong, "Review of natural fibre-reinforced hybrid composites," J. Reinf. Plast. Compos., vol. 37, no. 5, pp. 331348, 2018.

[15] M. N. Gururaja and H. Rao, “A Review on Recent Applications and Future Prospectus of Hybrid Composites," Int. J. Soft Comput. Eng., no. 16, pp. 2231-2307, 2012.

[16] E. Jayamani, K. H. Soon, and M. K. Bin Bakri, "Dielectric Properties of Pineapple Leaf Fiber Reinforced Epoxy Based Composites," Key Eng. Mater., vol. 730, no. 1, pp. 42-47, 2017.

[17] F. Hanan, M. Jawaid, and M. T. Paridah, "Oil Palm EFB/Kenaf Fibre Reinforced Epoxy Hybrid Composites: Dimension Stability Behaviours," IOP Conf. Ser. Mater. Sci. Eng., vol. 368, p. 012024, 2018.

[18] M. Singh Bahra, V. K. Gupta, and L. Aggarwal, "Effect of Fibre Content on Mechanical Properties and Water Absorption Behaviour of Pineapple/HDPE Composite," Mater. Today Proc., vol. 4, no. 2, pp. 3207-3214, 2017.

[19] G. Bujjibabu, V. C. Das, M. Ramakrishna, and K. Nagarjuna, "ScienceDirect Mechanical And Water Absorption Behavior Of Natural Fibers Reinforced Polypropylene Hybrid Composites," Mater. Today Proc., vol. 5, no. 5, pp. 12249-12256, 2018.

[20] N. Venkateshwaran, A. ElayaPerumal, A. Alavudeen, and M. Thiruchitrambalam, "Mechanical and water absorption behaviour of banana/sisal reinforced hybrid composites," Mater. Des., vol. 32, no. 7, pp. 4017-4021, 2011.

[21] A. Athijayamani, M. Thiruchitrambalam, U. Natarajan, and B. Pazhanivel, "Effect of moisture absorption on the mechanical properties of randomly oriented natural fibers/polyester hybrid composite," Mater. Sci. Eng. A, vol. 517, no. 1-2, pp. 344-353, 2009.

[22] S. Mukhopadhyay and R. Srikanta, "Effect of ageing of sisal fibres on properties of sisal - Polypropylene composites," Polym. Degrad. Stab., vol. 93, no. 11, pp. 2048-2051, 2008.

[23] Z. N. Azwa, B. F. Yousif, A. C. Manalo, and W. Karunasena, "A review on the degradability of polymeric composites based on natural fibres," Mater. Des., vol. 47, pp. 424-442, 2013.

[24] E. Jayamani, S. Hamdan, M. R. Rahman, and M. K. Bin Bakri, "Comparative study of dielectric properties of hybrid natural fiber composites," Procedia Eng., vol. 97, no. June, pp. 536-544, 2014.

[25] Y. Li, M. Cordovez, and V. M. Karbhari, "Dielectric and mechanical characterization of processing and moisture uptake effects in E-glass / epoxy composites," vol. 34, pp. 383-390, 2003.

[26] P. Li, Y. Tao, and S. Q. Shi, "Effect of Fiber Content and Temperature on the Dielectric Properties of Kenaf Fiberfilled Rigid Polyurethane Foam,” BioResources, vol. 9, no. 2009, pp. 2681-2688, 2014.

[27] E. Jayamani, S. Hamdan, R. Rahman, and M. K. Bin, "Dielectric Properties of Lignocellulosic Fibers reinforced Polymer Composites : Effect of Fiber Loading and Alkaline Treatment," Mater. Today Proc., vol. 2, no. 4-5, pp. 2757-2766, 2015.

[28] K. S. Chun and S. Husseinsyah, "Mechanical and thermal properties of coconut shell powder filled polylactic acid biocomposites : effects of the filler content and silane coupling agent," 2012.

[29] I. S. Aji, E. S. Zainudin, K. Abdan, and S. M. Sapuan, "Journal of Composite Materials,” no. April, 2013.

[30] I. Ben Amor, H. Rekik, H. Kaddami, M. Raihane, M. Arous, and A. Kallel, "Effect of palm tree fiber orientation on electrical properties of palm tree fiber-reinforced polyester composites," J. Compos. Mater., vol. 44, no. 13, pp. 1553-1568, 2010.

[31] M. F. Goes, M. A. Sinhoreti, S. Consani, and M. A. Silva, "Morphological effect of the type, concentration and etching time of acid solutions on enamel and dentin surfaces.," Braz. Dent. J., vol. 9, no. 1, pp. 3-10, 1998. 
[32] H. P. S. Abdul, M. Jawaid, A. Hassan, M. T. Paridah, and A. Zaido, "Oil Palm Biomass Fibres and Recent Advancement in Oil Palm Biomass Fibres Based Hybrid Biocomposites," Compos. Their Appl., 2012.

[33] R. Chaudhary, R. C. Singh, and R. M. Singari, "Mechanical Prospects of Bio Fibers," no. March 2015, 2013.

[34] M. R. Y. Hamid, M. H. Ab Ghani, and S. Ahmad, "Effect of antioxidants and fire retardants as mineral fillers on the physical and mechanical properties of high loading hybrid biocomposites reinforced with rice husks and sawdust," Ind. Crops Prod., vol. 40, no. 1, pp. 96-102, 2012.

[35] D. B. Dittenber and H. V. S. Gangarao, "Critical review of recent publications on use of natural composites in infrastructure," Compos. Part A Appl. Sci. Manuf., vol. 43, no. 8, pp. 1419-1429, 2012.

[36] K. L. Fung, R. K. Y. Li, and S. C. Tjong, Interface modification on the properties of sisal fiber-reinforced polypropylene composites, vol. 85, no. 1. 2002.

[37] M. M. Kabir, H. Wang, K. T. Lau, and F. Cardona, "Chemical treatments on plant-based natural fibre reinforced polymer composites: An overview," Compos. Part B Eng., vol. 43, no. 7, pp. 2883-2892, 2012.

[38] B. Wang, S. Panigrahi, L. Tabil, and W. Crerar, "Pre-treatment of flax fibers for use in rotationally molded biocomposites," J. Reinf. Plast. Compos., vol. 26, no. 5, pp. 447-463, 2007.

\section{BIOGRAPHIES OF AUTHORS}
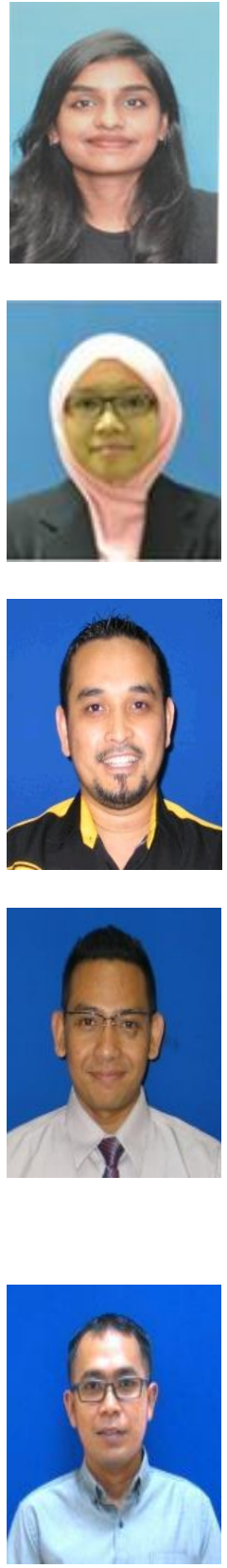

Nishanthi Sunthrasakaran was born in Johor Bahru, Johor, Malaysia, in 1993. She received Diploma in Electrical Engineering and B.Eng in Electrical Engineering from Universiti Tun Hussein Onn Malaysia (UTHM) in 2013 and 2017 respectively. Currently, she is pursuing a PhD degree in Electrical Engineering at Universiti Tun Hussein Onn Malaysia (UTHM). Her academic interest includes of polymer bio composite insulation, dielectrics and insulation condition monitoring. She is registered with the Board of Engineers Malaysia (BEM). She is also graduate member of Institution of Engineers, Malaysia (IEM).

Nor Akmal Mohd Jamail is a lecturer of Universiti Tun Hussein Onn Malaysia since 2008. She received the Bachelor degree in Electrical Engineering from Universiti Teknologi Malaysia in 2005, M.Eng in Power System from Universiti Tun Hussein Onn Malaysia in 2007 and Ph.D. in High Voltage Engineering from Universiti Teknologi Malaysia, in 2015. Her research interests include condition monitoring of polymer nanocomposite insulation for HV purpose, dielectrics and electrical insulation. She is registered with the Board of Engineers Malaysia (BEM).

R. Abd-Rahman received M.Eng degree (Electrical \& Electronic) and $\mathrm{PhD}$ (High Voltage) from Cardiff University, U.K. in 2008 and 2012 respectively. He is currently a Senior Lecturer in the Faculty of Electrical \& Electronic Engineering at Universiti Tun Hussein Onn Malaysia (UTHM). His research interests include dielectric materials, outdoor insulator and discharge phenomenon. He is a Chartered Engineer U.K (CEng) and member of engineering institution such as IET (MIET), IEEE (MIEEE) as well as Board of Engineers Malaysia (BEM).

Md Nor Ramdon Bin Baharom was born in Kuala Lumpur, Malaysia on August 1978. He received the B.E. degree in Electrical and Electronic Engineering from School of Computing, Creative Technologies \& Engineering, Leeds Metropolitan University, United Kingdom in 2004. He received the Ph.D. degree from Electrical Energy and Power Systems Group of the School Of Electrical and Electronic Engineering at the University of Manchester in 2010. He is currently working as a lecturer in Department of Power Electrical Engineering of the Faculty of Electrical and Electronic Engineering, Universiti Tun Hussein Onn Malaysia (UTHM), Malaysia. His major research interests include high-voltage insulations, overhead-line design, lightning structure protection, electrical environmental interference impact, composite insulators and flashover of contaminated insulators.

Qamarul Ezani Kamarudin is an instructor of Universiti Tun Hussein Onn Malaysia since 2007. He received the Bachelor degree in Mechanical Engineering from Universiti Teknologi Malaysia in 2006. His research interests include wind turbine and wind energy harvesting technique and polymer nanocomposite insulation material. $\mathrm{He}$ is registered with the Board of Engineers Malaysia (BEM). 


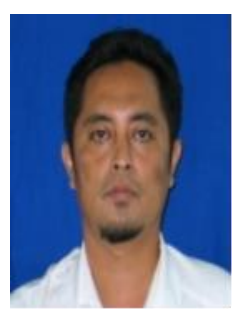

Ts. Mohamad Farid bin Hj Sies was born in Batu Pahat, Johor, in 1976. He received the B.Eng. degree in mechanical engineering from the University of Technology Malaysia (UTM), in 2007, and the Master of Mechanical Engineering and Ph.D. degrees in Mechanical Engineering from University Tun Hussein Onn Malaysia (UTHM), in 2013 and 2019, respectively. In 2008, he joined the Department of Mechanical Engineering, University Tun Hussein Onn Malaysia, as an instructor, and in 2016 became a senior Instructor. Since December 2017, he was lecture at UTHM. His current research interests include spray and atomization, ventilation, energy and materials. Ts. Dr. Mohamad Farid bin Hj Sies is a member of Malaysia Board of Technologists (MBOT), Board of Engineers Malaysia (BEM) and The Institution of Engineers, Malaysia.

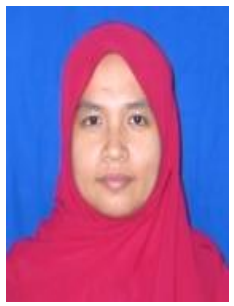

Ts. Dr. Wan Nur Azrina Binti Wan Muhammad obtained his B.Eng. and M.Sc. Degrees in Material Engineering from Universiti Sains Malaysia (USM) in 2000 and 2002, respectively, and a Ph.D. in Material Engineering from Nagaoka University of Technology, Japan, in 2011. Currently, she is a senior lecturer in the Faculty of Mechanical and Manufacturing Engineering at Universiti Tun Hussein Onn Malaysia (UTHM). His research interests include composite materials, powder metallurgy, magnesium-based composites, molten salt technology and heat recovery system. She is registered with the Board of Engineers Malaysia (BEM) and Malaysia Board of Technologists (MBOT). 